\title{
A INTERAÇÃO ENTRE O BIBLIOTECÁRIO E O LEITOR-OUVINTE NA CONTAÇÃO DE HISTÓRIAS
}

\author{
LA INTERACCIÓN ENTRE EL BIBLIOTECARIO Y EL \\ LECTOR-OYENTE EN CUENTACUENTOS
}

\begin{abstract}
Sueli Bortolin - bortolin@uel.br Doutora em Ciência da Informação pela Universidade Estadual Paulista (UNESP/Marília). Professora do Programa de Pós-Graduação em Ciência da Informação da Universidade Estadual de Londrina (UEL).

Vera Jussara Burghi - jussaraburghi@hotmail.com Bibliotecária, atuando como analista sociocultural na Secretaria da Educação do Estado de São Paulo na cidade de Santo Anastácio.
\end{abstract}

\section{RESUMO}

Introdução: Este artigo é resultado de um trabalho de pesquisa bibliográfica, em que a Contação de histórias em biblioteca escolar é destacada como uma atividade cultural e pedagógica possível de ser desenvolvida no cotidiano da Biblioteca Escolar.

Objetivo: Fomentar reflexões a respeito das ações que envolvem a leitura no espaço da biblioteca escolar, em especial, das narrativas de histórias realizadas pelos bibliotecários.

Metodologia: Método bibliográfico, tendo como base a literatura publicada em língua portuguesa.

Resultados: É de fundamental importância que os acadêmicos de Biblioteconomia e os bibliotecários participem de discussões acerca de práticas orais como forma de interação e acolhimento dos pequenos leitores no espaço da biblioteca.

Conclusões: Ainda há pouco envolvimento dos bibliotecários com as mais diversas narrativas, provavelmente porque a rotina de trabalho nas bibliotecas escolares ainda exige uma atuação maior desse profissional nos serviços administrativos e técnicos, ficando nas mãos dos professores a disseminação da literatura.

Palavras-chave: Bibliotecário. Contação de Histórias. Biblioteca Escolar. 


\section{INTRODUÇÃO}

Inicialmente devemos considerar que as histórias, em especial, as universais, chamadas de clássicos, ao utilizar o Era uma vez, "arrastam" as crianças (e os adultos também) da vivência momentânea até um passado longínquo. As que não se enquadram no gênero contos de fada também poderão fazer isso, com o acréscimo de que também levam para um futuro visionário de usos e costumes, muitas vezes inimagináveis.

A Contação de histórias, dentre suas inúmeras atribuições pedagógicas e culturais, é uma brincadeira. Podemos considerá-la como uma atividade ancestral. Hoje, em decorrência de tantos recursos tecnológicos acessíveis no mundo, muitas experiências para crianças já vem prontas, assim, o ato de brincar, acaba sendo uma opção que fica em segundo plano e muitas crianças esquecem as formas de brincar que exigem delas iniciativas físicas e cognitivas.

Essa atividade deve ser entendida como uma possibilidade em que a criança se exercita fisicamente e intelectualmente, além de ser uma brincadeira, isto é, um ato divertido e prazeroso, tanto para a criança, quanto para o narrador.

Quando um mediador oral narra brilhantemente uma história, torna essa atividade envolvente. Uma história contada com emoção, marca a criança pelo resto da vida. Assim, o ato de contar histórias é fundamental, uma vez que, as histórias fazem parte da natureza humana. Elas têm o poder de congregar e emocionar, interiorizar conceitos e preconceitos, portanto devem ser muito bem escolhidas.

Além disso, o ato de contar histórias age também como elemento que facilita o processo contínuo da aprendizagem. Ajuda a construir o ato imaginário, despertando no aluno uma expectativa que, por exemplo, a história de Os três porquinhos proporciona. A maioria da população mundial traz consigo (em múltiplas versões) esta e outras histórias fabulosas. A identificação com essas narrativas denota indícios de vivências pessoais, que em suas singularidades - dizem quem somos e no leva a compreensão de novos valores.

$\mathrm{Na}$ atualidade devemos aliar o ato de contar histórias aos novos modos de leitura, isto é, àqueles que propagam as narrativas literárias utilizando a oralidade 
midiatizada. ${ }^{1}$ Em um mundo permeado por tvs, celulares e tablets, o aluno não consegue ficar apegado apenas ao livro físico, palpável.

Assim o bibliotecário escolar precisa adotar metodologias que facilitem o cumprimento do seu papel de difusor cultural e também educacional, contribuindo para a formação de um espaço dinâmico, humanizado, onde os alunos frequentando, sejam leitores aptos ao desenvolvimento de competências socioemocionais importantes para sua formação como cidadãos.

Para tanto, há que se construir uma forte interação entre os profissionais da Educação e os seus mediandos.

\section{INTERAÇÃO ENTRE O BIBLIOTECÁRIO E O LEITOR-OUVINTE}

A busca da etimologia da palavra interação nos leva à dois termos inter+ação, isto é, uma ação entre duas ou mais pessoas. Na atualidade se utiliza também a palavra interatividade, mas não há consenso se essas palavras são sinônimas. Nas leituras realizadas nos últimos tempos, fica evidente que a palavra interatividade, frequentemente, está atrelada à relação homem-máquina.

Nosso interesse é a interação social homem-homem, visto que queremos refletir a respeito de como ela acontece na relação leitor-bibliotecário e como esse profissional age, quais são suas normas ou código sociais no momento da mediação oral da literatura na escola.

Para Bortolin (2010, p. 137) esse ato pode ser conceituado "[...] como toda intervenção espontânea ou planejada de um mediador de leitura visando a aproximar o leitor-ouvinte de textos literários seja por meio da voz viva ou da voz mediatizada."

$\mathrm{Na}$ escola a mediação deve ser mais afetiva para que se possa contribuir com a formação de leitores num país que, na nossa expectativa, ainda precisa criar e intensificar a cultura de uma leitura constante e diversificada. Vale destacar a palavra afetividade (ou como defende Paulo Freire amorosidade ${ }^{2}$ ), pois muitas vezes ela é mal interpretada na escola, sendo que em algumas é até proibido de chamar $\mathrm{a}(\mathrm{o}) \operatorname{professor}(\mathrm{a})$ de tia(o). Acreditamos que não são as denominações que

\footnotetext{
${ }^{1}$ Expressão criada por Arantes (2014, p. 26) "[...] para significar a voz que se revela, se manifesta, se externa por meio das tecnologias midiáticas. A oralidade midiatizada transpassa o espaço e o tempo, pois é capaz, através das ferramentas tecnológicas, de ser eternizada."

${ }^{2}$ A respeito desse assunto leia Pedagogia do Oprimido de Paulo Freire.
} 
interferem em uma interação de qualidade, e que a interação não se efetiva, principalmente na escola, sem que no mínimo haja um ponto convergente entre o mediador e o mediando. Nesse momento, parece necessário buscar o significado de interação.

No Dicionário Breve da Informação e da Comunicação publicado em Lisboa Portugal, Rodrigues (2000, p. 71) afirma que interacção é "Acção mútua realizada por dois ou mais agentes físicos, biológicos ou humanos, visando objetivos e estratégias comuns." Para ampliar essa ideia buscamos, no Dicionário de Ciências Sociais da Fundação Getúlio Vargas (FGV) a definição de interação social, nele consta: "Interação social designa a influência recíproca dos atos de pessoas e grupos, o que geralmente se dá por meio da comunicação. [...]" (FUNDAÇÃO..., 1986 , p. 624, grifo nosso).

Assim, se me comunico, palavra que vem do latim communico com o sentido de "[...] pôr em comum; reunir; associar" (BUSARELLO, 2005, p. 61); devo fazer isso, na biblioteca escolar, com e não para os alunos. Nessa perspectiva a atuação do bibliotecário, além de ser mais dinâmica, torna-se essencial, visto que possibilita a partilha de conhecimentos, de acolhimento e o sentimento de pertencimento ao espaço. Três verbos fundamentais: partilhar, acolher e pertencer, palavras que voltaram a ser pronunciadas na atualidade, talvez no bojo da discussão a respeito da alteridade. ${ }^{3}$

Pensar e praticar a mediação escolar é estar imbuído das reflexões humanísticas de pensadores como Lev Semenovitch Vygotsky e Paulo Freire. Assim, ao abordar a interação nos apropriamos de Vygotsky por meio da primorosa obra de Teresa Cristina Rego. Para ele:

[...] o desenvolvimento pleno do ser humano depende do aprendizado que realiza num determinado grupo cultural, a partir da interação com outros indivíduos da sua espécie. [...] A criança só aprenderá a falar se pertencer a uma comunidade de falantes, ou seja, as condições orgânicas (possuir o aparelho fonador), embora necessárias, não são suficientes para que o indivíduo adquira a linguagem. (REGO, 2013, p. 71).

\footnotetext{
${ }^{3}$ Para Frei Betto, alteridade, "É ser capaz de apreender o outro na plenitude da sua dignidade, dos seus direitos e, sobretudo, da sua diferença. Quanto menos alteridade existe nas relações pessoais e sociais, mais conflito ocorrem." (BETTO, [2014], Não paginado).
} 
Desse texto podemos inferir que não há interação sem comunicação e que na situação da criança, que se encontra em fase inicial de leitura e comunicação oral a interação e a mediação tornam-se vitais para ela. Uma das formas mais propulsora da apreensão da palavra é a mediação oral, seja por meio das músicas, dos contos, das conversas, das brincadeiras e jogos. A literatura de diferentes áreas e também as reportagens jornalísticas reúnem relatos de que crianças que, sendo criadas isoladas do contato humano, não adquirem a capacidade de falar e, em muitos casos de conviver socialmente.

\footnotetext{
Desde o nascimento, o bebê está em constante interação com os adultos, que não só asseguram sua sobrevivência, mas também medeiam a sua relação com o mundo. Os adultos procuram incorporar as crianças à sua cultura, atribuindo significado às condutas e aos objetos culturais que se formaram ao longo da história. (REGO, 2013, p. 59).
}

No coletivo, querer dialogar é querer interagir (ou será que querer interagir é querer dialogar?). As duas formas de compor o enunciado, nos leva a perceber que essas são práticas constantes no espaço escolar. Quanto mais realizamos essas ações, maior possibilidade de intercâmbio, seja ele cultural, social e psicológico. Esse aspecto é analisado por Paulo Freire da seguinte forma:

[...] É no respeito às diferenças entre mim e eles ou elas, na coerência entre o que faço e o que digo, que me encontro com eles ou com elas. É na minha disponibilidade à realidade que construo a minha segurança, indispensável à própria disponibilidade. É impossível viver a disponibilidade à realidade sem segurança mas é impossível também criar a segurança fora do risco da disponibilidade. (FREIRE, 1999, p. 152, grifos do autor).

Nossa defesa é que na escola, especificamente na biblioteca escolar as narrativas de histórias precisam, cada vez mais, estar presentes evidenciando uma diversidade de textos, que devem ser oralizados de forma ética e afetiva. Na esteira de Paulo Freire o fato de estar disponível, engrandece o ato de mediar, o mediador e, em consequência, o espaço da biblioteca escolar. 


\section{CONTAÇÃO DE HISTÓRIAS NA BIBLIOTECA ESCOLAR}

É preciso que o bibliotecário fique atento para a importância de se trabalhar com atividades orais recreativas, visando facilitar a aproximação de seus alunos com a leitura, e consequentemente melhor uso do acervo.

A oralidade praticada continuamente no espaço da biblioteca escolar é um caminho seguro que leva às várias leituras em diferentes suportes e linguagens. Sendo assim de suma importância que o bibliotecário promova o seu acervo literário, por intermédio de atividades culturais.

Nóbrega (2002, p. 129) elenca os dois tipos de dinamização de acervos: atividades variadas de leitura (textos e manifestações artísticas diversificadas) e espaço convidativo. Essa dinamização se concretiza na criação de ambiências de leitura, onde ocorrem ações planejadas, uma vez que, segundo Silva (1981, p. 42) a "[...] leitura é uma atividade essencial a qualquer área do conhecimento e mais essencial à própria vida do Ser Humano."

O bibliotecário que atua no espaço da biblioteca escolar deve apurar a sua sensibilidade no momento em que está narrando uma história, isso contribui para que ocorra a interação entre ele e o leitor-ouvinte ${ }^{4}$, propiciando a propagada interação, discutida na seção interior. Essa é uma condição que leva a criança a imergir na história narrada e, consequentemente ter vontade de buscar novas leituras.

Por outro lado, o mediador tem a responsabilidade de ser o fio condutor entre o aluno que está ouvindo a história com as etapas da narrativa, início, meio e fim, podendo provocar uma sensação de estar juntos, de partilha, em que o público possa colher impressões, reinventar e remodelar as histórias.

Nesse sentido, o bibliotecário precisa de um arsenal de informação que o subsidiará na escolha do gênero textual, nas intervenções no ambiente, na compreensão do público a ser focado. Antes de narrar é preciso entender profundamente o texto, se apaixonar por ele, a fim de transmitir a sensação de encantamento por meio das palavras. Em geral, se foi bom para quem contou, dificilmente será ruim para quem ouve.

${ }^{4}$ Aquele que lê também com os ouvidos. 
Narrando uma história acompanhada de elementos como: sons, objetos e brincadeiras o bibliotecário possibilita a criança se entreter, interagir, brincar com as palavras, sentindo diferentes sensações.

É ouvindo histórias que se pode sentir (também) emoções importantes, como a tristeza, a raiva, a irritação, o bem-estar, o medo, a alegria, o pavor, a insegurança, a tranqüilidade, e tantas outras mais, e viver profundamente tudo o que as narrativas provocam em quem as ouve - com toda a amplitude, significância e verdade que cada uma delas fez (ou não) brotar... Pois é ouvir, sentir e enxergar com os olhos do imaginário! (ABRAMOVICH, 1989, p. 17).

O mediador na escola, se quiser, acaba interferindo, com suas ações, nas relações familiares, podendo trazer para dentro da biblioteca, mesmo que de maneira não presencial, os pais. Azevedo (2004, p. 158) discorre:

Ao entrar em contato com um conto maravilhoso, uma quadrinha ou um dito de sabedoria popular, o estudante talvez pense: "Peraí! Meus pais conhecem isso! Isso eu já ouvi! Isso faz sentido para mim!" A partir daí, é perfeitamente possível imaginar que tal aluno volte para casa, conte o conto que aprendeu na escola e, no dia seguinte, traga outros contados pelo pai ou por algum parente.

Além disso, o ato de contar histórias é um trabalho que envolve as artes de modo prazeroso e reflexivo, é uma atividade cultural. Segundo a contadora de histórias Fernanda Munhão (2013) "As histórias não servem para nada e é por isso que elas servem para tudo, assim é: medo, alegria, angústias e idealizações."

O contador de histórias tem como função principal levar as crianças à despertarem sua imaginação; proporcionar alternativas para novas escolhas de leitura, e até mesmo contar ou (re)contar histórias a partir de contos populares ou literários que foram lidos, assim, exercitando suas capacidades de improvisação e percepção.

As histórias estimulam o desenvolvimento das funções cognitivas e do pensamento, visto que permite ao indivíduo compreender e interpretar melhor a si mesmo e a realidade, sendo a Contação de histórias uma atividade com infinitas possibilidades de interações. 
Outro aspecto é a mudança que pode provocar na imagem do bibliotecário escolar, pois ele para de pensar apenas nas tarefas rotineiras, sendo capaz de construir momentos de Contação de histórias.

Nossa avaliação é de que o bibliotecário valorizando as narrativas de histórias, como uma atividade essencial para o mundo da leitura, evidencia o acervo que está sob a sua responsabilidade.

É possível aliar a leitura de um texto retirado de um livro com os elementos cênicos e com as atividades interativas, que possibilitam maior fixação e entendimento. As histórias podem por meio dos devaneios ajudar as crianças a enfrentar os problemas da vida.

Para ressaltar isso Silva (2008, p. 128) afirma:

Aqui, "ao vivo", o contador, cantador ou encantador precisa saber controlar seus gestos, pois estes estão sendo observados e são significantes importantes que compõem, ao final, o "texto" falado. Seu tom de voz, altura, sotaque tem de estar a serviço do sentido preciso do que se deseja comunicar. Precisa estar atento à sua platéia, a seu ambiente e à energia circulante, posto que seus interlocutores passivos são capazes de agir e interagir -, se não o compreenderem ou o considerarem insultuoso podem variar ou simplesmente irem embora. Seu discurso falado, justamente por ser falado é efêmero, se dissipa no exato momento em que é cantado, isto é, narrado, "contado". Mas, por outro lado, e exatamente por causa disso, se presta a improvisos, a variações e a influências de toda uma constelação imaginativa característica do verdadeiro artista e da beleza própria da arte.

Vale destacar novamente a interação, pois esta precisa ser trabalhada, isto é, a criança não deve ser considerada um mero ouvinte, mas sim um elemento vivo dentro da própria narrativa. A interação favorece um melhor entrosamento, quebrando uma possível barreira entre o bibliotecário narrador e o ouvinte.

Estabelecer uma nova perspectiva para a Contação de histórias dentro do espaço da biblioteca escolar é primordial. Aliar uma atividade interativa que proporcione ao ouvinte a possibilidade de se expressar. Será a chance de reconstruir o que para ele era abstrato e o trazendo para o mundo real, além de compartilhar tal fato com os demais ouvintes.

Há que se valorizar também as atividades interativas pós-contação. Muitos profissionais que trabalham na biblioteca não têm a preocupação de unir a Contação 
com uma atividade interativa. Nessa perspectiva propõe-se a realização de ações culturais no espaço da biblioteca escolar.

\begin{abstract}
Para que o ouvinte possa sentir a história, e construir suas imagens, interagindo com o texto, o contador deve também sentir, enxergar com detalhes e cores as cenas da história, enquanto narra. Ter domínio do texto, das emoções por ele provocadas, do olhar para que os ouvintes acreditem nos acontecimentos e fatos do texto, é de fundamental importância para qualquer história, independente dos recursos utilizados pelo contador. (CAFÉ, 2000, p. 33).
\end{abstract}

O bibliotecário como agente mediador oral deve provocar interesse no aluno que está ouvindo a história, proporcionando momentos singulares de mediação e estabelecendo assim um momento de troca. O importante é que o bibliotecário, no momento de escolha de uma história, pergunte ao texto: o que você me comunica? O que você tem para me presentear? Será que o leitor-ouvinte vai gostar como estou gostando desse texto? A Contação de histórias tem esse benefícios para quem conta e para quem escuta.

O ato de contar histórias é uma atividade que pode ser desenvolvida pelo bibliotecário e também pelos profissionais e comunidade escolar: professores, pedagogos, pais e demais familiares. É uma atividade imprescindível para a escola, em especial, na biblioteca escolar, pois é nela que deverão ser formados os leitores.

Portanto, cabe ao profissional da biblioteca implantar essa prática oral, numa intervenção adequada e em ambiente acolhedor. Além disso, deve se preocupar com a escolha do texto, com a faixa etária, a ocasião, além de atividades recreativas e interativas adicionando outros elementos tais como: onomatopeias, músicas e também recreação; atividades que contribuem para a formação da criança em idade escolar.

Visando apoiar o desenvolvimento da capacidade criativa e original da criança, o bibliotecário mediador deve estimular, a partir das imagens construídas em sua mente no momento da oralização de histórias, atividades que podem propiciar o senso crítico, o despertar da curiosidade em descobrir novas leituras.

\title{
4. PROCEDIMENTOS METODOLÓGICOS
}

Considerando que as publicações na temática Contação de Histórias existente na literatura brasileira é vasta, fizemos um recorte e realizamos nossa 
revisão de literatura apenas em documentos em língua portuguesa e nas áreas de Educação, Biblioteconomia e Letras.

O tema em questão exigiu a abordagem qualitativa e a pesquisa bibliográfica. Para não ser confundida com revisão de literatura nos apropriamos do pensamento de Witter (1990, p. 26), quando afirma:

A pesquisa bibliográfica é um tipo específico de pesquisa documental centrada na análise de suportes bibliográficos (textos), diferindo da revisão da literatura pela especificidade de objetivos e procedimentos. É uma pesquisa em si mesma e não parte de outras, como ocorre com a revisão.

Este trabalho ao ser executado, respeitou as etapas necessárias para a pesquisa bibliográfica, isto é, localização, compilação, fichamento, interpretação e redação. Apesar do conhecimento de que esta metodologia compreende a "[...] bibliografia já tornada pública em relação ao tema de estudo, desde publicações avulsas, boletins, jornais, material cartográfico, até meios de comunicação orais: rádio, gravações em fita magnética e audiovisuais: filmes e televisão" (MARCONI; LAKATOS, 2013, p. 57), optamos exclusivamente em utilizar as fontes impressas, porém de maneira diversificada e abrangendo o período de quatro décadas.

Essa delimitação temporal deu-se pelo fato do livro - Contar histórias: uma arte sem idade de Betty Coelho ter sido publicado na década de 80 e se transformado em um "Manual" para os contadores de histórias em terras brasileiras.

A respeito desse livro vale destacar o comentário de Tânia Maria Piacentin:

Quem se interessar pelo livro exatamente porque tem "modelinhos" e "receitas", vai se frustrar, pois não encontrará coisas prontas e acabadas, certezas e dogmas. A única garantia que Betty oferece é o seu testemunho e o seu exemplo de que contar histórias é uma experiência fascinante. (PIACENTIN, 1988, p. 103).

Esse também foi o nosso objetivo, não trazer fórmulas acabadas, mas partilhar experiências e refletir a respeito de nossa prática como contadoras de histórias.

\section{RESULTADOS}


A pesquisa bibliográfica, em geral, seduz o pesquisador que gosta de investigações teóricas ou que tenha uma tendência em fazer comparações, seja ela apontando avanços ou uma mera especulação histórica. No caso desse trabalho a nossa intenção, apesar de não usarmos demarcações explícitas como datas períodos, foi destacar o pensamento de alguns pesquisadores brasileiros que estão se dedicando ao ato de narrar histórias em diferentes ambientes.

Não tivemos a preocupação em apontar equívocos ou teorias que atualmente são desconsideradas pelas investigações a respeito de narrativas orais. Nosso trajeto bibliográfico visou destacar fundamentalmente que a prática cotidiana dos contadores de histórias na escola, além de essencial ao desenvolvimento social, psicológico e cultural dos educandos, contribui na interação do bibliotecário com o leitor-ouvinte.

Mesmo que há em nosso discurso um aparente sentimento de soberba, insistimos para que os acadêmicos de Biblioteconomia e os bibliotecários busquem discussões e coloquem em prática ações de narrativas orais, visando o acolhimento dos pequenos leitores no espaço da biblioteca e, consequentemente despertando neles o sentimento de pertença (apontado anteriormente). Acreditamos com muita intensidade que assim efetivamente poderemos formar leitores desejosos de estar em um ambiente de múltiplas leituras.

\section{CONSIDERAÇÕES FINAIS}

Vivemos em uma sociedade letrada e globalizada, onde as crianças, desde 0 seu nascimento recebem inúmeros estímulos que cabem aos profissionais que atuam na escola mediar, favorecendo e fomentando novas formas de construção de aprendizagens. Acreditamos que durante a oralização de histórias existe a possibilidade de a criança construir novos pontos de vista a respeito de determinados assuntos.

Diante dessas abordagens é possível perceber o quão é importante o bibliotecário lançar questionamentos, desafios e questionamentos no momento da narração. Ele precisa permitir que os alunos frequentadores do espaço da biblioteca escolar também assumam o espaço de contadores de histórias, com suas características e encantamentos. 


\section{REFERÊNCIAS}

ABRAMOVICH, Fanny. Literatura infantil: gostosuras e bobices. São Paulo: Scipione, 1989.

ARANTES, Fernanda Mecking. Uso da oralidade na mediatização dos websites de bibliotecas públicas. Londrina, 2014. 108f. Dissertação (Mestrado em Ciência da Informação) - Universidade Estadual de Londrina. Programa de Pós-Graduação em Ciência da Informação. Londrina, 2014.

AZEVEDO, Ricardo. Formas literárias populares e formação de leitores. In: BARBOSA, Márcia H. S.; RETTENMAIER, Miguel; Rosing, Tânia M. K. (Org.). Leitura, Identidade e patrimônio cultural. Passo Fundo: UPF, 2004.

BORTOLIN, Sueli. Mediação Oral da Literatura: A voz dos bibliotecários lendo ou narrando. 2010.232 f. Tese (Doutorado em Ciência da Informação) - Faculdade de Filosofia e Ciências, universidade Estadual Paulista, Marília, 2010.

BUSARELLO, Raulino. Dicionário básico latino-português. 6.ed. Florianópolis: Editora UFSC, 2005.

CAFÉ, Angela Barcellos. Dos contadores de história e das histórias dos contadores. Campinas: 2000. 102 f. Dissertação (Mestrado em Educação Física) Universidade Estadual de Campinas, Campinas, 2000.

COELHO, Betty. Contar histórias: uma arte sem idade. São Paulo, Ática. 1986.

FREIRE, Paulo. Pedagogia da autonomia: saberes necessários à prática educativa. 11.ed. São Paulo: Paz e Terra, 1999.

FUNDAÇÃO GETÚLIO VARGAS. Dicionário de Ciências Sociais. Rio de Janeiro: FGV, 1986.

MARCONI, Marina de Andrade; LAKATOS, Eva Maria. Técnica de pesquisa: planejamento e execução... 7. ed. São Paulo: Atlas, 2013.

MUNHÃO, Fernanda. PROFISSÃO: contadora de histórias. Diário de Ourinhos, Ourinhos. 1 abr.2013. Entrevista concedida por Fernanda Munhão. Disponível em: <http://www.diariodeourinhos.com.br/noticia.asp?codnot=10101>. Acesso em: 26 out.2014.

NOBREGA, Nanci Gonçalves da. De livros e bibliotecas como memória do mundo: dinamização de acervos. YUNES. Eliana. (Org.). Pensar a leitura: complexidades. Rio de Janeiro: Ed. PUC-Rio; São Paulo: Loyola, 2002.

PIACENTIN, Tânia Maria. Resenhas: quem conta um conto... Perspectiva R. CED, Florianópolis, v. 5, n. 10, p. 103-104, jan./jun. 1988. Disponível em: <https://periodicos.ufsc.br/index.php/perspectiva/article/viewFile/10044/9228>. 
REGO, T. C. Vygotsky- Uma perspectiva Histórico-Cultural da Educação. 7 ed. Petrópolis: Vozes, 1999.

\section{RODRIGUES, Adriano Duarte. Dicionário breve da informação e da} comunicação. Lisboa: Editorial Presença, 2000.

SILVA, Ezequiel Teodoro. Ler é, antes de tudo, compreender. In: 0 ato de ler: fundamentos psicológicos para uma nova pedagogia da leitura. São Paulo: Cortez, 1981. p. $42-45$.

SILVA, René Marc da Costa (Org.). Cultura popular e educação. Brasília: SEEDIMEC, 2008. (Salto para o FuturolTV Escola).

WITTER, Geraldina Porto. Pesquisa bibliográfica, pesquisa documental e busca de informação. Estudos de Psicologia, Campinas, v.7, n. 1, p.5-30, jan./jul. 1990.

\section{Title}

The interaction between the librarian and the listener in storytelling

\section{Abstract}

Introduction: This article is the result of a bibliographic research, in which the storytelling in school library is highlighted as a cultural and educational activity that could be developed in school library's daily routine.

Objective: Encourage reflections about the actions that involve reading in the school library, specially the narratives of stories performed by librarians.

Methodology: Bibliographic research based on published literature in Portuguese.

Results: It is of the utmost importance that faculty of librarianship and librarians participate in discussions about oral practices as a way of interaction and welcoming young readers in the school library.

Conclusions: Still, there is little involvement of librarians with narratives, probably because the work routine in school libraries still requires that this professional gets involved on administrative and technical issues a lot, letting the responsibility of spreading literature to the teachers.

Keywords: Librarian. Storytelling. School Library.

\section{Título}

La interacción entre el bibliotecario y el lector-oyente en cuentacuentos

\section{Resumen}

Introducción: Este artículo es resultado de un trabajo de búsqueda bibliográfica, en que la narración de historias en biblioteca escolar es señalada como una actividad cultural y pedagógica posible de ser desarrollada en el cotidiano de la Biblioteca Escolar. 
Objetivo: Fomentar reflexiones a respecto de las acciones que involucren la lectura en el entorno de la biblioteca escolar, en específica, las narrativas de historias realizadas por los bibliotecarios.

Metodología: Método bibliográfico, tomando por base la literatura publicada en lengua portuguesa.

Resultados: Es de fundamental significación que los académicos de Biblioteconomía y los bibliotecarios participen de discusiones sobre las prácticas orales como forma de interacción y acogida de los pequeños lectores en el ambiente de la biblioteca.

Conclusiones: Todavía existe poco envolvimiento de los bibliotecarios con las más distintas narrativas, probablemente porque la rutina de trabajo en las bibliotecas escolares aún exige una actuación mayor de este profesional en los servicios administrativos y técnicos, permaneciendo en las manos de los profesores la diseminación de la literatura.

Palabras clave: Bibliotecario. Narración de Historias. Biblioteca Escolar.

Recebido em: 12.11.2014

Aceito em: 22.12.2014 